\title{
Peningkatan Mutu Tanah Liat Sebagai Bahan Baku Pembuatan Batu Bata di Kelurahan Bukaka, Kabupaten Bone, Sulawesi Selatan
}

\author{
Irzal Nur $^{1 *}$, Sufriadin ${ }^{1}$, Purwanto ${ }^{1}$, Asran Ilyas ${ }^{1}$, Aryanti Virtanti Anas ${ }^{1}$, \\ Nirmana Fiqra Qaidahiyani ${ }^{1}$, Halilintar Rangga Swara ${ }^{1}$, Reski Fausi Amanda ${ }^{1}$ \\ Departemen Teknik Pertambangan, Fakultas Teknik Universitas Hasanuddin ${ }^{1}$ \\ irzal.nur@eng.unhas.ac.id*
}

\begin{abstract}
Abstrak
Di Kelurahan Bukaka, Kabupaten Bone, Sulawesi Selatan terdapat industri pembuatan batu bata dengan bahan baku tanah liat (lempung), yang dikelola oleh masyarakat setempat secara turun-temurun dan telah berlangsung selama puluhan tahun. Berdasarkan hasil obsevasi lapangan, diidentifikasi masalah bahwa produk yang dihasilkan secara umum belum memenuhi standar kualitas batu bata yang baik, yang ditetapkan dalam Standar Industri Indonesia. Tujuan kegiatan pengabdian masyarakat ini adalah melakukan serangkaian pengujian laboratorium untuk mengetahui dan memberikan rekomendasi peningkatan kualitas bahan baku (tanah liat) maupun produk batu bata yang dihasilkan, agar dapat memenuhi standar kualitas yang dibutuhkan. Metode-metode pekerjaan laboratorium yang dilakukan meliputi analisis mineralogi (XRD) dan kimia (XRF) pada sampel-sampel lempung, serta uji dimensi, uji bakar, warna, kadar garam, daya serap, kuat tekan, dan uji dering pada sampel-sampel batu bata. Hasil pengujian menunjukan bahwa material lempung bahan baku gerabah tersusun oleh mineral felspar, kuarsa, kaolinit, dan kalsit; dengan kandungan besi yang tinggi $\left(\mathrm{Fe}_{2} \mathrm{O}_{3}\right.$ mencapai $\left.8,85 \%\right)$, sehingga direkomedasikan untuk dilakukan penurunan kadar dengan metode magnetic separator. Dimensi batu bata yang diproduksi belum memenuhi standar ukuran, sehingga disarankan untuk melakukan peningkatan ukuran, terutama dari segi lebar dan tebal. Dari segi pembakaran, direkomendasikan untuk ditingkatkan temperatur dan durasinya, agar kualitas batu bata yang dihasilkan lebih bagus/kuat. Batu bata juga memiliki daya serap yang rendah, hanya sekitar $0,5-0,6 \mathrm{gr} / \mathrm{dm}^{2} / \mathrm{menit}$, sehingga perlu penanganan yang lebih baik pada saat penyampuran material bahan bakunya. Hasil uji kuat tekan batu bata menunjukkan nilai rata-rata $24,47 \mathrm{~kg} / \mathrm{cm}^{2}$, yang mengindikasikan batu bata Kelas 25 (SII-0021-78), dengan kualitas yang baik dari segi bunyi dering.
\end{abstract}

Kata Kunci: Bata; Lempung; Besi; Magnetic Separator; Mineralogi.

\begin{abstract}
In Bukaka area, Bone Regency, South Sulawesi, Indonesia, a small scale industry of red-bricks with clay as the raw material is exist, which have been operated by the local people in generations for decades. From field observation, problems were identified related to the quality of the bricks produced, which mostly not fulfill the quality standards. The purpuse of this community service activiy is to conduct a series of laboratory tests to define and formulate recommendations in order to improve the quality of the raw material and the bricks. Methods of laboratory works performed in this avtivity include mineralogical analysis (XRD) and chemical analysis (XRF) for clay samples, as well as dimension test, baking test, colour, saline content, absorbtion, compressive strength and sound test for the bricks. The results showed that the clay material composed of feldspar, quartz, kaolinite, and calcite; with a high content of iron $\left(\mathrm{Fe}_{2} \mathrm{O}_{3} 8.85 \%\right)$, thus it is recommended to conduct a decreasing grade of the iron content using magnetic separator method. Dimension of the bricks produced by the local workers were generally far below the quality standard; thus it is recommended to conduct an increasing size of the bricks, particulary in their thickness and width. For the bricks baking, it is recommended to perform an increasing temperature and duration of the baking in order to gain a better quality. Absorbtion of the bricks were also averagely low, 0.5-0.6 gr/dm ${ }^{2} /$ minute, thus it needs to be treated carefully at the time of the raw material mixing. Uncompressed strength test of the bricks resulted average value of $24.47 \mathrm{~kg} / \mathrm{cm}^{2}$, which indicated a Class-25 type of the bricks, and having a good quality regarding their sound.
\end{abstract}

Keywords: Bricks; Clay; Iron; Magnetic Separator; Mineralogy. 


\section{Pendahuluan}

Di Kelurahan Bukaka, Kecamatan Tanete Riattang, Kabupaten Bone, Sulawesi Selatan terdapat industri pembuatan batu bata dengan bahan baku tanah liat (tanah lempung), yang dikelola oleh masyarakat setempat secara turun-temurun dan telah berlangsung selama puluhan tahun. Kegiatan penambangan tanah liat sebagai bahan baku pembuatan batu bata ini dilakukan oleh masyarakat secara perorangan dengan dasar kepemilikan lahan, yang dikontrol dan dikoordinasi oleh Lurah setempat. Pada saat kunjungan awal ke lokasi industri yang dilakukan pada bulan Januari 2020, tercatat sebanyak 32 usaha penambangan dan pembuatan batu bata dengan luas wilayah sekitar 7 (tujuh) ha. Areal penambangan tanah liat untuk bahan baku pembuatan batu bata ini berada di sekitar pemukiman dan perkantoran, khususnya Kantor Kelurahan Bukaka, di mana pondok-pondok pembakarannya dikonstruksi dari kayu dan atap nipah (Gambar 1).

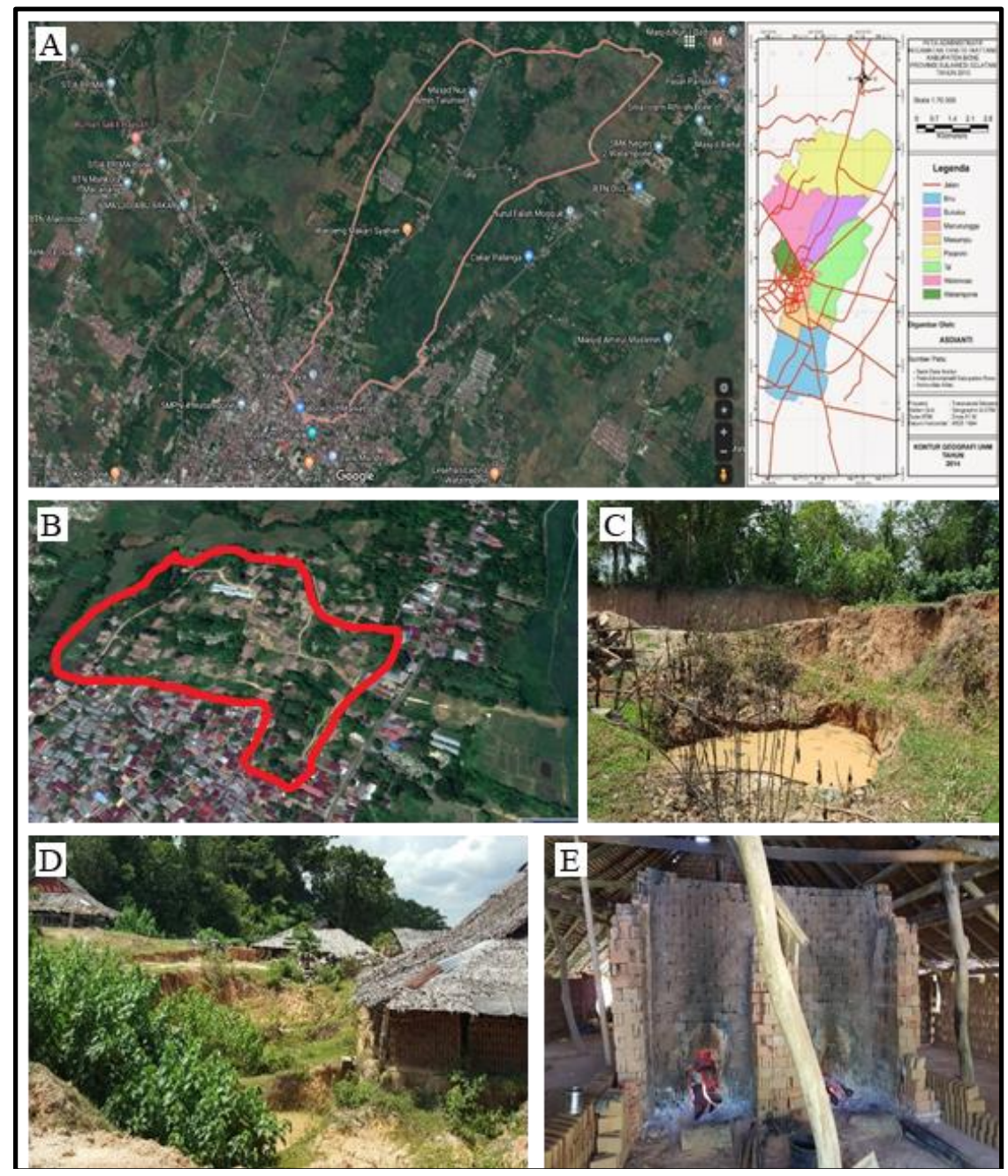

Gambar 1. (A) Peta lokasi Kelurahan Bukaka, Kecamatan Tanete Riattang, Kabupaten Bone, Sulawesi Selatan. (B) Kenampakan Google Earth lokasi penambangan dan industri pembuatan batu bata di Kelurahan Bukaka (area berwarna merah). (C) Salah satu lokasi penambangan tanah liat untuk bahan baku pembuatan batu bata. (D) Pondok-pondok pembakaran batu bata. (E)

Tungku pembakaran batu bata. 
Sisi-sisi batu bata yang tidak rata atau bergelombang menunjukkan kualitas yang tidak bagus dan tidak sesuai dengan standar industri batu bata yang baik, yang jika digunakan dapat menyebabkan bangunan menjadi tidak kokoh (beban yang berada di atasnya mudah/dapat tergelincir). Warna batu bata yang tidak seragam mengindikasikan material (bahan baku) tanah liat yang digunakan sebelum dibakar, tidak tercampur secara merata, serta suhu pembakaran yang tidak optimal. Demikian juga, suara yang tidak nyaring pada saat batu bata dibenturkan mengindikasikan temperatur pembakaran yang optimal.

Berdasarkan uraian hasil obsevasi awal tersebut, maka produk batu bata yang dihasilkan oleh pelaku industri kecil di Kelurahan Bukaka secara umum belum memenuhi standar kualitas batu bata yang baik, yang telah ditetapkan dalam Standar Industri Indonesia maupun Standar Nasional Indonesia untuk batu bata (SII-0211-78, SNI S-04-1991, dan SNI 15-2094-2000). Selain itu, untuk industri pembuatan keramik atau gerabah (termasuk batu bata), Departemen Perindustrian melalui SNI No.1145-1984, telah menerbitkan standar kualifikasi kualitas berdasarkan persentasi kandungan oksida-oksida tertentu untuk lempung atau felspar yang digunakan sebagai bahan baku, yaitu: $\left(\mathrm{K}_{2} \mathrm{O}+\mathrm{Na}_{2} \mathrm{O}\right) 6-15 \%, \mathrm{Fe}_{2} \mathrm{O}_{3}$ maksimal 0,8\%, dan $\mathrm{CaO}$ maksimal $1 \%$.

Berdasarkan uraian latar belakang tersebut, yang pada kegiatan Pengabdian Masyarakat ini merupakan permasalahan mitra dari Tim Pengabdian Masyarakat Universitas Hasanuddin, maka tujuan kegiatan ini adalah melakukan pengujian laboratorium yang sistematis dan terukur untuk mengetahui dan memberikan rekomendasi peningkatan kualitas bahan baku (tanah liat) maupun produk batu bata yang dihasilkan oleh industri batu bata merah tradisional di Kelurahan Bukaka, agar dapat memenuhi standar kualitas yang dibutuhkan, sesuai dengan yang disyaratkan pada Standar Industri Indonesia maupun Standar Nasional Indonesia untuk batu bata. Kegiatan peningkatan kualitas tersebut meliputi: analisis/karakterisasi kandungan mineral dan komposisi kimia dari tanah liat (tanah lempung) yang digunakan sebagai bahan baku pembuatan batu bata; pengujian kualitas batu bata dari segi ukuran/dimensi dan kesikuan agar dapat sesuai dengan yang disyaratkan pada Modul 5 dan Modul 6 SII-0021-78 dan SNI 15-2094-2000; di samping itu juga akan dilakukan berbagai kegiatan pengujian lainnya yang merupakan uji-uji standar untuk mengetahui kualitas batu bata, yang meliputi: uji kuat tekan, uji pembakaran, uji kadar garam, uji penyerapan, uji dering, dan uji warna (Rahmi dan Syarief, 2014; Salami et al., 2010; Abdulloh, 2004). Selanjutnya, pada bagian akhir dirumuskan rekomendasi solusi untuk meningkatkan mutu bahan baku dan juga produk bata yang dihasilkan, berdasarkan hasil-hasil pengujian yang telah dilakukan.

\section{Latar Belakang Teori}

Kegiatan Pengabdian Masyarakat ini difokuskan pada peningkatan mutu tanah liat sebagai bahan baku pembuatan batu bata. Tanah liat atau lempung (clay) adalah fragmen mineral atau partikel detrital yang disusun umumnya oleh fragmen kristalin dari mineral lempung, dengan ukuran yang lebih kecil dari ukuran butir lanau sangat halus (very fine silt grain), serta diameter yang lebih kecil dari 1/256 mm (4 mikron, atau 0,00016 inci). Definisi lain dari lempung adalah sedimen natural atau soft rock yang bersifat loose, earthy, dan berbutir sangat halus dengan ukuran butir utama lempung atau partikel koloidal dan dicirikan oleh tingginya tingkat plastisitas, dengan kandungan utama berupa mineral lempung (minimal 25\%) yang berasosiasi dengan kuarsa, serta mineral-mineral felspar, karbonat, dan material ferruginous (besi/ $\mathrm{Fe}^{+}$) yang telah terdekomposisi, disertai dengan material-material pengotor lainnya; bersifat plastis, merupakan massa yang dapat/mudah dibentuk (moldable) jika bercampur dengan air, 
mempertahankan bentuknya tersebut jika sudah kering, dan menjadi kaku, membatu, serta keras secara permanen jika dibakar (Twenhofel, 1937; Pettijohn, 1957).

Lempung atau tanah liat dapat dimanfaatkan dalam berbagai macam kegunaan, seperti porselen, ubin, saniter, tembikar/keramik, gerabah (termasuk batu bata), penyaringan (filtration), pengilangan/penyulingan minyak (oil refining), dan industri kertas (Suhala dan Arifin, 1997). Khusus untuk pembuatan keramik atau gerabah, Departemen Perindustrian melalui SNI No.1145-1984, telah menerbitkan standar kualifikasi kualitas berdasarkan persentasi kandungan oksida-oksida tertentu untuk lempung/felspar, seperti dapat dilihat pada Tabel 1.

Tabel 1. Standar kualifikasi kimia lempung/felspar untuk berbagai kegunaan

\begin{tabular}{cccc}
\hline Jenis Oksida & Porselen (\%) & Saniter (\%) & Gerabah (\%) \\
\hline $\mathrm{K}_{2} \mathrm{O}+\mathrm{Na}_{2} \mathrm{O}$ & $6,0-15,0$ & $6,0-15,0$ & $6,0-15,0$ \\
$\mathrm{Fe}_{2} \mathrm{O}_{3}$ (maks.) & 0,5 & 0,7 & 0,8 \\
$\mathrm{TiO}_{2}$ (maks.) & 0,3 & 0,7 & - \\
$\mathrm{CaO}$ (maks.) & 0,5 & 0,5 & 1,0 \\
\hline
\end{tabular}

Pada Tabel 1 terlihat bahwa salah satu faktor yang memengaruhi tingkat kualitas gerabah adalah kandungan $\mathrm{Fe}_{2} \mathrm{O}_{3}$ (atau kandungan $\mathrm{Fe}^{+}$atau besi), di mana kadarnya tidak boleh lebih dari 0,8\%; bahkan menurut Klasifikasi Feldspar Corporation USA (Harben, 1995), kadar maksimal oksida besi $\left(\mathrm{Fe}_{2} \mathrm{O}_{3}\right)$ yang disyaratkan untuk pembuatan gerabah berkisar 0,067-0,08\%

Secara geologi, endapan lempung (tanah liat) yang terdapat di lokasi kegiatan merupakan anggota dari Formasi Walanae yang tersebar luas di wilayah Kabupaten Bone bagian timur (Watampone dan sekitarnya). Formasi ini disusun oleh unit-unit batuan sedimen yang terdiri atas batupasir yang berselingan dengan batulanau, tufa, napal, batulempung, konglomerat, dan batugamping. Batupasir dan batulempung (yang merupakan sumber dari endapan tanah liat atau lempung residual di lokasi kegiatan) umumnya berwarna kecoklatan, berbutir halus sampai kasar, banyak mengandung kuarsa, dan karbonatan (Sukamto, 1982).

\section{Metode}

Kegiatan Pengabdian Masyarakat ini secara umum terbagi atas dua tahapan, yaitu kegiatan lapangan dan kegiatan (uji) laboratorium. Berikut diuraikan setiap tahapan tersebut.

\subsection{Kegiatan Lapangan}

Kunjungan lapangan dilakukan untuk melihat langsung kondisi penambangan tanah liat (lempung) dan pembuatan batu bata di lokasi kegiatan, melakukan wawancara dengan para pelaku industri, dan melakukan pengambilan sampel tanah liat serta produk batu bata yang dihasilkan, untuk kepentingan uji laboratorium (Gambar 2.A).

Pengambilan sampel tanah liat dilakukan pada 3 (tiga) lokasi penambangan (Gambar 2.B), dengan jumlah sampel yang diambil sebanyak 5 (lima) buah, masing-masing dengan kode sampel BK-1A dan BK-1B (dari lokasi 1), BK-2 (dari lokasi 2), dan BK-3A dan BK-3B (dari lokasi 3). Sedangkan sampel-sampel batu bata, baik yang sudah dicetak dan belum dibakar maupun yang sudah dibakar, dilakukan pada 1 (satu) lokasi pembuatan batu bata (lokasi yang sama dengan Gambar 2.A). 


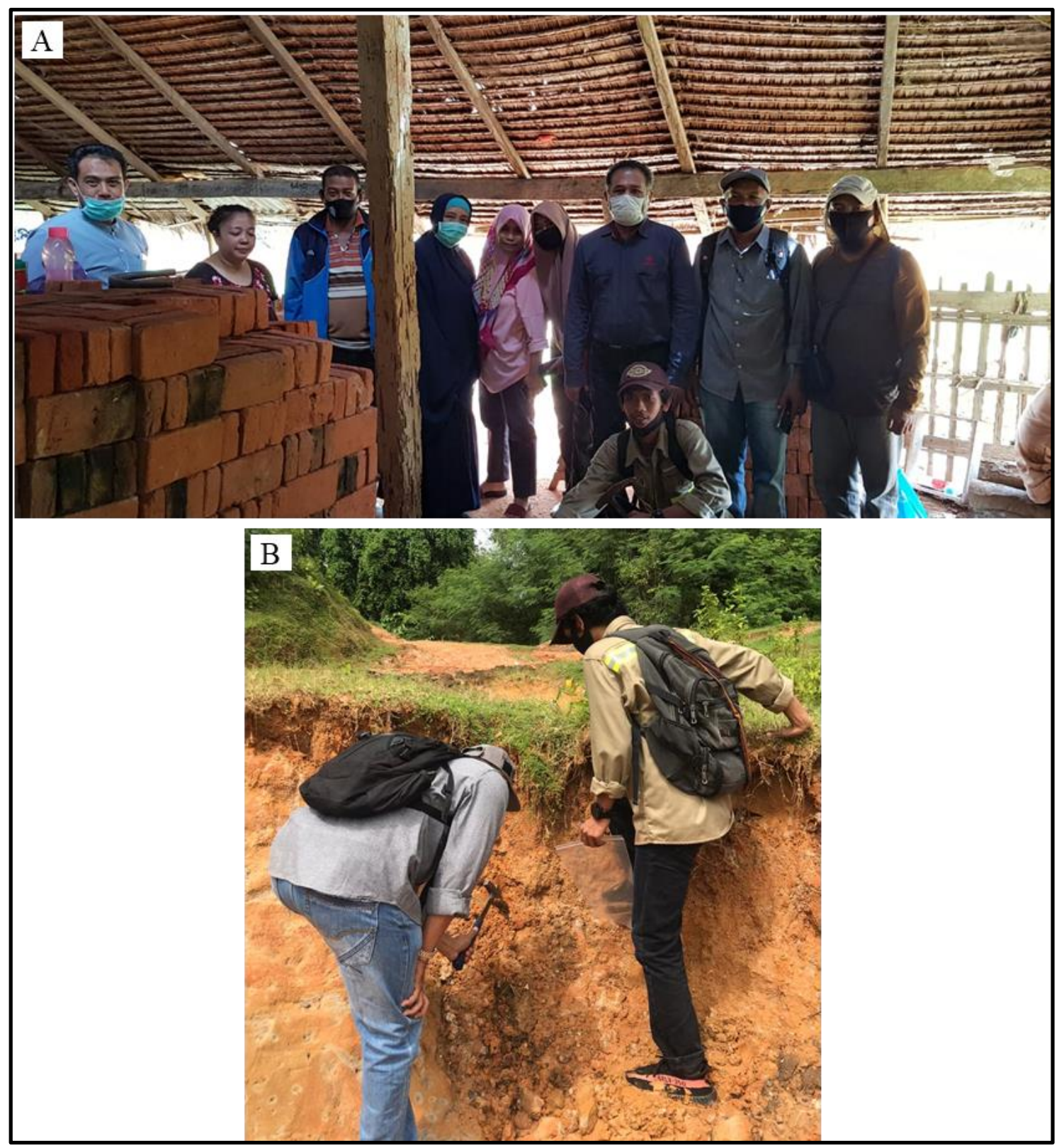

Gambar 2. (A) Kunjungan lapangan di lokasi pembuatan batu bata di Kelurahan Bukaka, Kabupaten Bone. (B) Pengambilan sampel tanah liat di lokasi penambangan.

\subsection{Kegiatan Laboratorium}

Tahapan ini bertujuan untuk melakukan berbagai jenis pengujian dan analisis untuk mengarakterisasi dan menguji kualitas bahan baku tanah liat maupun produk batu bata yang dihasilkannya. Jenis-jenis kegiatan pengujian dan analisis/karakterisasi material yang dilakukan di laboratorium adalah sebagai berikut:

1) Analisis mineralogi; Bertujuan untuk mengetahui komposisi mineral dari tanah liat (lempung) bahan baku pembuatan batu bata, yang dilakukan dengan metode $X$-ray diffraction analysis (XRD). Alat XRD yang digunakan adalah mesin diffractometer tipe Shimadzu 
XRD-7000L. Interpretasi data difraktogram hasil analisis XRD dan penentuan spesies mineralnya dilakukan dengan batuan software Impact Match! 3.9.

2) Analisis kimia; Bertujuan untuk mengetahui komposisi kimia dari tanah liat (lempung) bahan baku pembuatan batu bata, yang dilakukan dengan metode $X$-ray fluorescence spectrometry (XRF). Alat yang digunakan adalah mesin XRF tipe Shimadzu EDX-720.

3) Pengujian/pengukuran dimensi dan kesikuan sampel-sampel batu bata; Pengujian (pengukuran) ini didasarkan pada referensi Modul-5a, Modul-5b, dan Modul-6 SII-0021-78 (Rahmi dan Syarief, 2014).

4) Uji bakar (pembakaran/pemanggangan) dan uji warna; Pembakaran/pemanggangan sampelsampel cetakan batu bata dilakukan menggunakan tungku pembakaran elektrik skala laboratorium (electric furnace). Sedangkan uji warna dilakukan dengan melihat langsung warna batu bata yang telah dibakar dan dibandingkan dengan warna cetakan batu batanya sebelum dibakar (Mardiyati dan Harjana, 2010; Rahmi dan Syarief, 2014; Andayono, 2017).

5) Uji kadar garam; Uji ini dilakukan baik pada sampel-sampel batu bata dari lokasi industri, maupun batu bata hasil eksperimen. Metode pengujian kadar garam ini dilakukan dengan cara meletakkan sampel batu bata secara vertikal di dalam wadah ember berisi air, di mana sebagian dari batu bata tersebut terendam dalam air dan sebagian tidak. Perendaman dilakukan selama seminggu. Pada proses ini, air akan terserap ke dalam batu bata lewat bagian yang terendam di dalam air, kemudian mengalir ke bagian atas, lalu menguap melalui permukaan batu bata yang kontak dengan udara. Dalam perjalanannya dari bawah ke atas, air di dalam batu bata akan membawa garam yang telah terlarut. Apabila permukaan batu bata mengandung garam, akan tampak bercak-bercak putih (Abdulloh, 2004).

6) Uji penyerapan (daya serap); Uji ini juga dilakukan baik pada sampel-sampel batu bata dari lokasi industri, maupun batu bata hasil eksperimen. Uji diawali dengan cara menimbang sampel batu bata kering $\left(\mathrm{M}_{\mathrm{d}}\right)$, kemudian direndam dalam air selama satu menit, lalu ditimbang lagi $\left(\mathrm{M}_{\mathrm{s}}\right)$. Daya penyerapannya (DP) kemudian dihitung dengan menggunakan persamaan: $\mathrm{DP}=\left(\mathrm{M}_{\mathrm{s}}-\mathrm{M}_{\mathrm{d}}\right) / \mathrm{L}$. Di mana $\mathrm{L}$ adalah luas permukaan batu bata (Rahmi dan Syarief, 2014).

7) Uji kuat tekan dan uji dering; Uji kuat tekan dilakukan menggunakan alat UCS (Unconfined Compression Strength) (Sukobar dkk., 2014; Halauddin, 2017). Sedangkan uji dering dilakukan dengan cara memegang dua sampel batu bata dan kemudian membenturkannya satu sama lain, dengan benturan yang tidak terlalu keras. Batu bata yang berkualitas baik akan mengeluarkan bunyi dering (Rahmi dan Syarief, 2014).

\section{Hasil dan Diskusi}

\subsection{Komposisi Mineral Tanah Liat}

Hasil analisis XRD pada ke lima sampel tanah liat (lempung) di lokasi pengabdian menunjukkan komposisi mineral felspar, kuarsa, kaolinit, dan kalsit (Gambar 3). Hasil ini konsisten dengan karakteristik batupasir dan batulempung anggota Formasi Walanae (yang merupakan sumber dari material tanah liat di lokasi kegiatan), yang seperti telah diuraikan oleh Sukamto (1982), banyak mengandung kuarsa, dan karbonatan (dicirikan dengan kehadiran mineral kalsit). Di samping itu, kaolinit dan felspar juga merupakan mineral-mineral penyusun material (batuan) sedimen yang umumnya berukuran lempung (Tucker, 2003). 


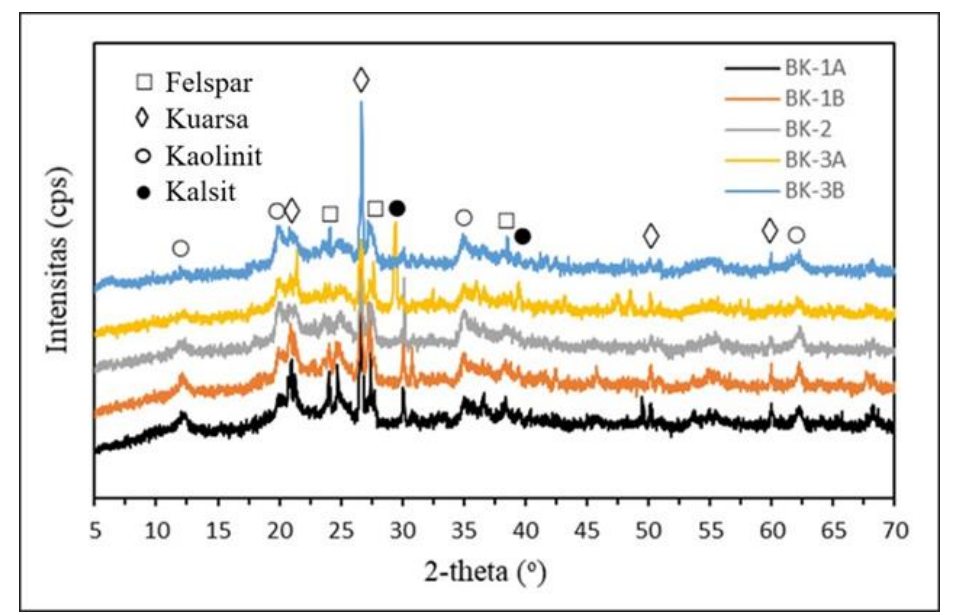

Gambar 3. Difraktogram hasil analisis XRD ke-lima sampel tanah liat (BK-1A, BK-1B, BK-2, BK-3A, BK-3B) yang menunjukkan komposisi mineral felspar, kuarsa, kaolinit, dan kalsit.

\subsection{Komposisi Kimia Tanah Liat}

Komposisi kimia 6 (enam) unsur mayor (major elements) hasil analisis XRF pada ke lima sampel tanah liat (lempung) di lokasi kegiatan dapat dilihat pada Tabel 2.

Tabel 2. Hasil analisis komposisi kimia sampel-sampel tanah liat dengan metode XRF

\begin{tabular}{crrrrr}
\hline \multirow{2}{*}{ Unsur } & \multicolumn{5}{c}{ Sampel; Satuan dalam \% } \\
\cline { 2 - 5 } & $\mathrm{BK}-1 \mathrm{~A}$ & $\mathrm{BK}-1 \mathrm{~B}$ & $\mathrm{BK}-2$ & $\mathrm{BK}-3 \mathrm{~A}$ & $\mathrm{BK}-3 \mathrm{~B}$ \\
\hline $\mathrm{Al}_{2} \mathrm{O}_{3}$ & 43,57 & 43,26 & 46,84 & 39,78 & 41,96 \\
$\mathrm{SiO}_{2}$ & 43,40 & 44,48 & 42,60 & 40,20 & 45,84 \\
$\mathrm{Fe}_{2} \mathrm{O}_{3}$ & 8,85 & 8,01 & 6,89 & 8,49 & 7,50 \\
$\mathrm{~K}_{2} \mathrm{O}$ & 1,59 & 1,68 & 1,78 & 1,57 & 2,25 \\
$\mathrm{CaO}$ & 0,82 & 0,78 & 0,87 & 8,79 & 1,08 \\
$\mathrm{TiO}_{2}$ & 0,70 & 0,74 & 0,72 & 0,84 & 0,94 \\
\hline
\end{tabular}

Dapat dilihat pada Tabel 2 bahwa pada ke-lima sampel kandungan besi $\left(\mathrm{Fe}_{2} \mathrm{O}_{3}\right)$ sangat tinggi, yaitu berkisar 6,89-8,85\%, di mana nilai ini jauh di atas ambang batas bahan baku gerabah (termasuk batu bata) yang baik, yaitu maksimum 0,8\% menurut SNI No.1145-1984 (Tabel 1). Sedangkan kandungan CaO-nya, yang berkisar 0,78-1,08\%, secara umum masih memenuhi syarat untuk menjadi bahan baku gerabah yang baik. Syarat kandungan $\mathrm{CaO}$ pada tanah liat yang baik menurut SNI No.1145-1984 adalah maksimal 1,0\% (Tabel 1). Dari ke-lima sampel yang dianalisis, hanya satu sampel yang kadar CaO-nya di atas 1,0\%, yaitu sampel BK-3B, sedangkan sampel-sampel lainnya memenuhi syarat (Tabel 2).

Sehingga, berdasarkan hal ini, sangat perlu untuk dilakukan treatment pada bahan baku tanah liat di lokasi kegiatan, terutama untuk menurunkan kadar besinya, sehingga produk batu bata yang dihasilkannya akan bermutu lebih baik. Treatment yang direkomendasikan adalah ekstraksi kandungan mineral-mineral besi dengan metode pemisahan secara magnetik (magnetic separation). 
Penelitian terdahulu yang telah melakukan analisis kimia untuk mengetahui kadar $\mathrm{Fe}^{+}$total $\left(\mathrm{Fe}_{2} \mathrm{O}_{3}+\mathrm{FeO}\right)$ dari bahan baku tanah liat di daerah Takalar, Sulawesi Selatan, dan uji bakar untuk mengetahui perbedaan mutu gerabah yang dihasilkan dari tanah liat yang tinggi dengan yang rendah kadar Fe-nya, menunjukkan bahwa tanah liat yang rendah kadar $\mathrm{Fe}^{+}$-nya akan menghasilkan gerabah yang lebih kuat daripada yang tinggi kadar $\mathrm{Fe}^{+}$-nya (perbandingan kuat lentur rata-rata 67,21 berbanding $53,89 \mathrm{~kg} / \mathrm{cm}^{2}$ ). Tanah liat yang digunakan sebagai bahan baku tidak dapat dipanaskan sampai suhu yang optimum $\left(900^{\circ} \mathrm{C}\right)$ untuk menghasilkan gerabah yang tahan atau berkuat-lentur tinggi. Kadar $\mathrm{Fe}^{+}$yang tinggi menyebabkan gerabah menjadi mudah melengkung atau tidak rata karena pada saat dibakar tingkat pemuaiannya tinggi (Umar, 2000).

Komposisi kimia lain yang disyaratkan oleh SNI No.1145-1984 untuk tanah liat yang baik sebagai bahan baku gerabah adalah kandungan $\mathrm{K}_{2} \mathrm{O}+\mathrm{Na}_{2} \mathrm{O}$ yang berkisar 6,0-15,0\% (Tabel 1). Pada kegiatan ini kandungan $\mathrm{Na}_{2} \mathrm{O}$ tidak dapat diketahui karena keterbatasan alat XRF yang digunakan (Tabel 2). Komposisi $\mathrm{TiO}_{2}$ tidak disyaratkan secara khusus pada SNI No.1145-1984 (Tabel 1). Komposisi $\mathrm{SiO}_{2}$ yang tinggi pada ke-lima sampel, berkisar 40,20-45,84\% (Tabel 2) mengindikasikan tingginya kandungan mineral kuarsa pada sampel-sampel tanah liat di daerah kegiatan, seperti yang telah dilaporkan oleh Sukamto (1982), dan telah ditunjukkan kehadirannya pada hasil analisis XRD (Gambar 3). Sedangkan kandungan $\mathrm{Al}_{2} \mathrm{O}_{3}$ kemungkinan besar merepresentasikan kehadiran mineral felspar yang juga telah ditunjukkan kehadirannya pada hasil analisis XRD (Gambar 3).

\subsection{Hasil Uji Dimensi Batu Bata}

Uji ini dilakukan untuk mengetahui apakah dimensi/ukuran batu bata yang dibuat di daerah kegiatan sudah sesuai dengan standar SII-0021-78. Pada uji ini dilakukan pengukuran panjang, lebar dan tebal dari 4 (empat) buah sampel batu bata dari lokasi kegiatan (sampel 1A, 1B, 2A, dan 2B). Hasil pengujian dan standar dimensi menurut SII-0021-78 dapat dilihat pada Tabel 3.

Tabel 3. Hasil uji dimensi batu bata dan standar dimensi menurut SII-0021-78

\begin{tabular}{cccccccc}
\hline \multicolumn{2}{c}{ Dimensi Batu Bata Lokasi Kegiatan $(\mathrm{mm})$} & \multicolumn{3}{c}{ Standar Dimensi Menurut SII-0021-78 $(\mathrm{mm})$} \\
\hline Sampel & Panjang & Lebar & Tebal & Modul & Panjang & Lebar & Tebal \\
\hline 1A & 184 & 42 & 10 & M-5a & 190 & 90 & 65 \\
1B & 185 & 41 & 10 & M-5b & 190 & 140 & 65 \\
2A & 185 & 42 & 10 & M-6 & 220 & 110 & 55 \\
2B & 185 & 43 & 10 & & & & \\
\hline
\end{tabular}

Pada Tabel 3 terlihat bahwa secara umum dimensi batu bata di lokasi kegiatan berukuran ratarata panjang $185 \mathrm{~mm}$, lebar $42 \mathrm{~mm}$, dan tebal $10 \mathrm{~mm}$. Ukuran ini sangat jauh menyimpang dari standar dimensi batu bata yang ditetapkan oleh SII-0021-78, baik pada Modul-5a, Modul-5b, maupun Modul-6 (Tabel 3). Pada ketiga dimensi diperlukan peningkatan ukuran, terutama pada dimensi lebar dan tebal.

\subsection{Hasil Uji Pembakaran dan Uji Warna Batu Bata}

Uji pembakaran dan uji warna batu bata dilakukan dengan membandingkan secara langsung warna batu bata sebelum dan sesudah dibakar. Batu bata yang telah melalui proses pembakaran yang baik akan berwarna merah atau kemerahan dan akan lebih cerah dibandingkan batu bata yang proses pembakarannya kurang baik (Andayono, 2017). Pada kegiatan pengabdian ini pembakaran batu bata di laboratorium dilakukan menggunakan electric furnace dengan suhu 
$1.200^{\circ} \mathrm{C}$. Hasil pembakaran selama $1 \times 24$ jam menunjukkan warna yang lebih merah daripada batu bata yang diambil di lokasi kegiatan, yang pembakarannya tidak dilakukan secara optimal. Perbandingan warna kedua batu bata dengan kondisi pembakaran yang berbeda tersebut dapat dilihat pada Gambar 4.

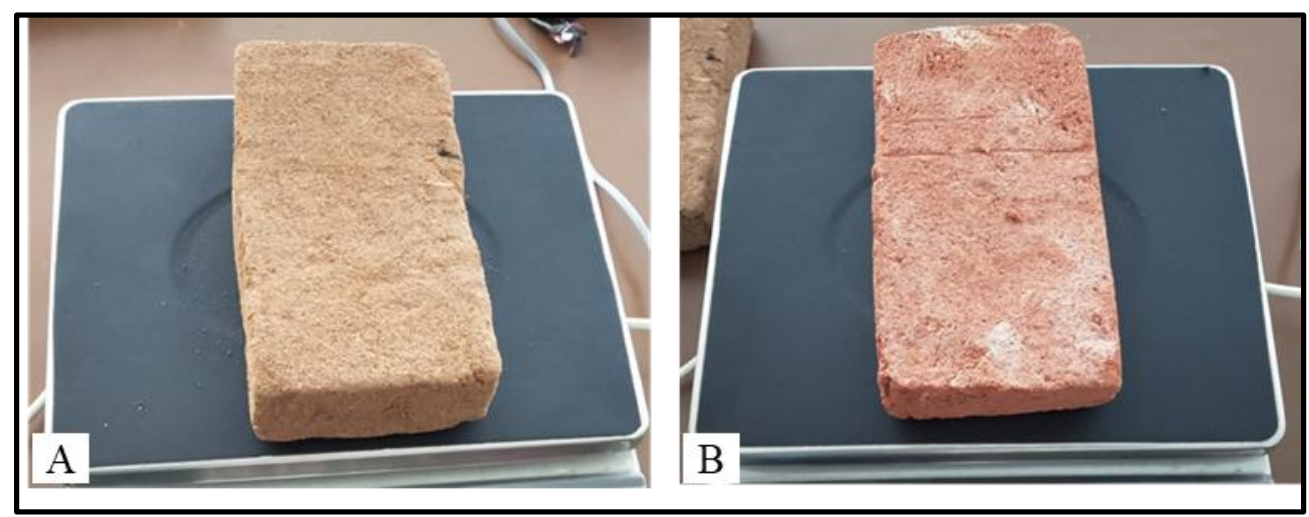

Gambar 4. (A) Batu bata dari lokasi pengabdian yang kondisi pembakarannya tidak optimal, sehingga warnanya tidak cerah dan tidak kemerahan. (B) Batu bata yang telah diuji bakar di laboratorium menggunakan electric furnace dengan temperatur $1.200^{\circ} \mathrm{C}$ selama $1 \times 24$ jam, menunjukkan hasil yang berwarna lebih cerah dan kemerahan.

\subsection{Hasil Uji Kadar Garam Batu Bata}

Uji kadar garam pada sampel batu bata dari daerah kegiatan menunjukkan adanya kandungan garam. Hal ini ditunjukkan dengan adanya buih di permukaan air setelah sampel batu bata di rendam selama 7 hari (Abdulloh, 2004); (Gambar 5).

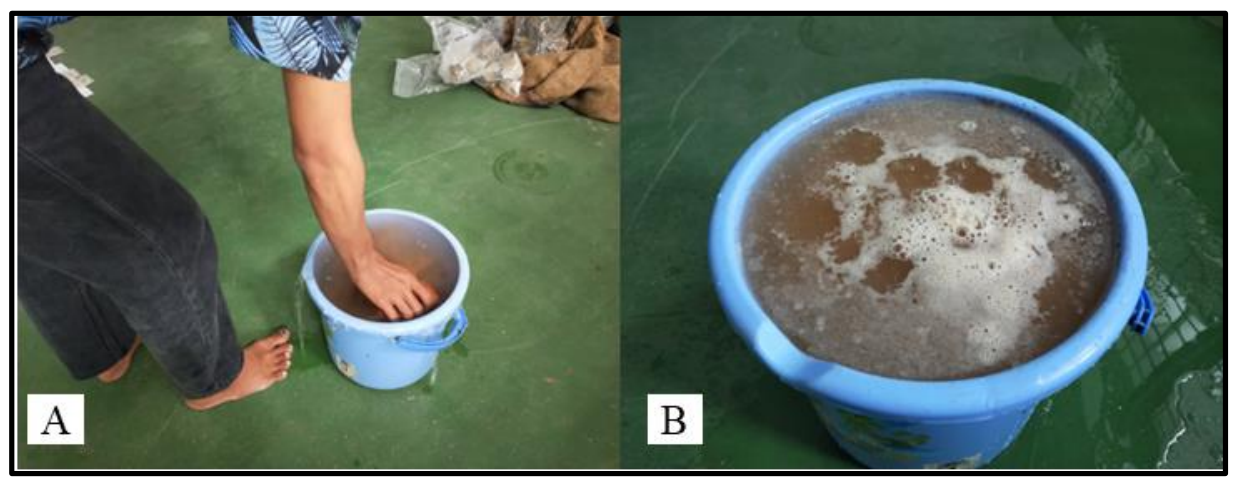

Gambar 5. (A) Perendaman sampel batu bata ke dalam air untuk pengujian kadar garam. (B) Kondisi air setelah direndam batu bata selama 7 hari, yang memperlihatkan buih-buih berwarna putih sebagai indikasi kandungan garam.

\subsection{Hasil Uji Daya Serap Batu Bata}

Hasil uji penyerapan pada 4 (empat) sampel batu bata dari lokasi kegiatan (sampel 1A, 1B, 2A, dan 2B) dengan proses dan persamaan yang telah diuraikan pada sub bab metode (3.2.6) (Rahmi dan Syarief, 2014), menunjukkan nilai daya serap yang lebih kecil daripada standar penyerapan yaitu $20 \mathrm{gr} / \mathrm{dm}^{2} /$ menit. Hal ini kemungkinan disebabkan oleh tingginya kandungan $\mathrm{SiO}_{2}$ (kuarsa) pada bahan baku pembuatan batu bata yang digunakan, sehingga menyebabkan tingginya daya ikat antar partikel. Seperti telah dijelaskan di bagian depan, lempung atau tanah liat di lokasi 
kegiatan merupakan anggota dari Formasi Walanae yang tinggi kandungan kuarsanya (Sukamto, 1982), dan ini juga sudah dibuktikan dengan hasil analisis XRD (Gambar 3). Selain kandungan $\mathrm{SiO}_{2}$ yang tinggi, faktor lain yang menyebabkan kecilnya daya serap dari batu bata pada daerah kegiatan yaitu kerapatan partikel pada batu bata. Kerapatan partikel batu bata ini bergantung pada proses pengadukan bahan bakunya serta pengeringan dan pembakaran batu batanya, di mana jika pori-porinya sangat rapat, akan menghasilkan daya serap yang rendah.

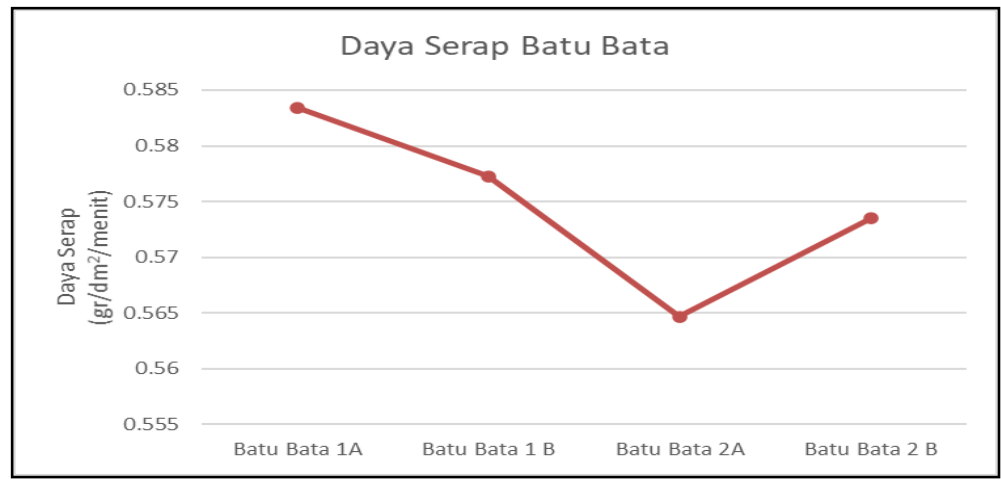

Gambar 6. Daya serap batu bata di daerah kegiatan pada 4 (empat) sampel yang menunjukkan nilai yang kecil (di bawah $0,585 \mathrm{gr} / \mathrm{dm}^{2} / \mathrm{menit}$ ).

\subsection{Hasil Uji Kuat Tekan dan Uji Dering Batu Bata}

Uji kuat tekan dilakukan pada 4 (empat) sampel batu bata pada dari daerah kegiatan. Hasilnya dapat dilihat pada Tabel 4. Rata-rata kuat tekan dari ke-empat sampel tersebut adalah 2,4 Mpa atau $24,47 \mathrm{~kg} / \mathrm{cm}^{2}$. Hal ini menunjukkan bahwa batu bata di daerah kegiatan termasuk dalam Kelas 25 pada Standar Industri Indonesia (SII-0021-78; Tabel 5).

Tabel 4. Nilai kuat tekan sampel-sampel batu bata

\begin{tabular}{cc}
\hline Sampel & Kuat Tekan (Mpa) \\
\hline 1A & 2,5 \\
1B & 2,3 \\
2A & 2,6 \\
2B & 2,2 \\
\hline
\end{tabular}

Tabel 5. Klasifikasi batu bata berdasarkan nilai kuat tekan (SII-0021-78)

\begin{tabular}{ccc}
\hline \multirow{2}{*}{ Kelas } & \multicolumn{2}{c}{ Kuat Tekan Rata-rata Batu Bata } \\
\cline { 2 - 3 } & $\mathrm{kg} / \mathrm{cm}^{2}$ & $\mathrm{~N} / \mathrm{mm}^{2}$ \\
\hline 25 & 25 & 2,5 \\
50 & 50 & 5 \\
100 & 100 & 10 \\
150 & 150 & 15 \\
200 & 200 & 20 \\
250 & 250 & 25 \\
\hline
\end{tabular}


Hasil uji dering yang dilakukan pada ke-empat sampel batu bata semuanya memperdengarkan bunyi dering jika dua sampel saling dibenturkan satu sama lain dengan pukulan yang tidak terlalu keras. Bunyi dering ini menunjukkan bahwa batu bata di daerah kegiatan mempunyai kualitas yang baik (Rahmi dan Syarief, 2014).

\section{Kesimpulan}

Beberapa kesimpulan dan rekomendasi peningkatan mutu produk batu bata di lokasi kegiatan pengabdian masyarakat ini adalah: di laboratorium adalah sebagai berikut:

1) Tanah liat (lempung) yang merupakan bahan baku pembuatan batu bata di lokasi kegiatan merupakan anggota unit-unit batupasir dan batulempung dari Formasi Walanae, yang mengandung mineral-mineral felspar, kuarsa, kaolinit, dan kalsit.

2) Hasil analisis kimia pada sampel-sampel tanah liat menunjukkan kandungan $\mathrm{CaO}$ yang memenuhi syarat untuk bahan baku pembuatan batu bata yang berkualitas baik, namun kandungan besinya $\left(\mathrm{Fe}_{2} \mathrm{O}_{3}\right)$ sangat tinggi, berkisar 6,89-8,85\%, yang melebihi ambang batas bahan baku batu bata yang baik (maksimum 0,8\%). Sehingga, direkomendasikan untuk melakukan penurunan kadar besi dengan metode magnetic separation, agar produk batu bata yang dihasilkan lebih berkualitas (lebih tahan, berkuat-lentur tinggi, dan tidak mudah patah atau melengkung).

3) Batu bata yang diproduksi oleh para pengrajin di lokasi kegiatan berdimensi rata-rata panjang $185 \mathrm{~mm}$, lebar $42 \mathrm{~mm}$, dan tebal $10 \mathrm{~mm}$. Ukuran ini sangat jauh menyimpang dari standar dimensi batu bata yang ditetapkan oleh Standar Industri Indonesia, sehingga direkomendasikan untuk dilakukan peningkatan ukuran, terutama pada dimensi lebar dan tebal.

4) Kondisi pembakaran batu bata di lokasi industri belum dilakukan secara optimal. Hasil uji bakar dan uji warna yang dilakukan di laboratorium pada kegiatan pengabdian masyarakat ini, dengan menggunakan electric furnace pada temperatur $1.200^{\circ} \mathrm{C}$ selama 24 jam, menghasilkan batu bata yang berkualitas lebih baik, terutama dari warna yang kemerahan. Sehingga direkomendasikan untuk melakukan pembakaran batu bata dengan temperatur yang lebih tinggi dan durasi pembakaran yang lebih lama.

5) Hasil uji menunjukkan bahwa sampel-sampel batu bata dari lokasi industri mengandung kadar garam; serta daya serap yang rendah, yaitu sekitar 0,5 hingga $0,6 \mathrm{gr} / \mathrm{dm}^{2} /$ menit (berada di bawah standar penyerapan: $20 \mathrm{gr} / \mathrm{dm}^{2} /$ menit). Hal ini terutama disebabkan kurang bagusnya penanganan bahan baku (tanah liat) pada saat penyampuran materialnya, sehingga porinya sangat rapat.

6) Hasil uji kuat tekan pada sampel-sampel batu bata menunjukkan nilai rata-rata 2,4 Mpa atau $24,47 \mathrm{~kg} / \mathrm{cm}^{2}$, yang mengindikasikan batu bata Kelas 25 (SII-0021-78). Sedangkan hasil uji deringnya menunjukkan kualitas yang baik (berdering ketika saling dibenturkan).

\section{Ucapan Terima Kasih}

Penulis menyampaikan terima kasih kepada Dekan Fakultas Teknik UNHAS atas dukungan dana yang diberikan melalui Hibah Laboratory Based Education (LBE) Tahun 2020, dengan Surat Kontrak No. 4696/UN4.7.2/PM.01.01/2020, sehingga Kegiatan Pengabdian Kepada Masyarakat ini dapat terlaksana. Ucapan terima kasih juga disampaikan kepada Mitra Kegiatan, yaitu Lurah Bukaka, Kabupaten Bone, Dra. Nurjannah Tinggi, M.Si. serta para pemilik usaha/industri pembuatan batu bata di lokasi pengabdian, yang telah membantu dan memfasilitasi kegiatan pengambilan sampel dan data lapangan. 


\section{Daftar Pustaka}

Abdulloh (2004), Evaluasi Teknik Uji Geser dan Uji Tekan dalam Kajian Pengaruh Kadar Air dan Penambahan Zat Limbun Terhadap Karakteristik Plastisitas Lempung Asal Dusun Sawoo, Kecamatan Kutorejo, Kabupaten Mojokerto. Bandung: Departemen Kimia Fakultas MIPA.

Andayono, T. (2017), Kualitas Batu Bata Pasca Sosialisasi Persyaratan Pokok Membangun Rumahlebih Aman Gempa. Jurnal Invotek, 17 (1), pp.81 - 88.

Halauddin (2017), Pengaruh Penambahan Sekam Padi dan Polimer Emulsi Poly Vynil Acetat Co Acrylic pada Tanah Lempung dengan Obyek Pengujian Kekuatan Batu Bata Menggunakan Metode Uniaxial. Jurnal Inersia, 9 (1), pp.39-46.

Harben, P.W. (1995), The Industrial Minerals Handbook; A Guide to Markets, Specifications \& Prices, Second Edition, Industrial Minerals Division, Metal Bullletin PLC, London, UK.

Mardiyati, I. dan Harjana (2010), Optimasi Suhu Pembakaran Batu Bata Merah dengan Penambahan Limbah Batubara untuk Meningkatkan Kualitas Batu Bata Merah. Prosiding Pertemuan Ilmiah XXIV HFI Jateng dan DIY, Semarang, 10 April 2010, hal. 317-322.

Pettijohn, F.J. (1957), Sedimentary Rocks, Second Edition, New York Harper, USA.

Rahmi, A. dan Syarief, A. (2014), Uji Kualitas Tanah Lempung dan Batu Bata Merah Garegeh Bukittinggi. Jurnal Riset Fisika dan Sains, 1(1), pp.28-32.

Salami, E., Tessari, U., Columbia, N. and Mastrocico, M. (2010), Improved Gravitational Grain Size Separation Method. Applied Clay Science, 48(4), pp.612-614.

Suhala, S. dan Arifin, M. (1997), Bahan Galian Industri, Pusat Penelitian dan Pengembangan Teknologi Mineral, Bandung, hal. 151-164.

Sukamto, R. (1982), Peta Geologi Lembar Pangkajene dan Watampone Bagian Barat, Sulawesi. Pusat Penelitian dan Pengembangan Geologi, Bandung.

Sukobar, Kuntjoro, Kusumastuti dan Sungkono (2014), Kesetaraan Kuat Tekan Batu Bata (Press) Asal Bangsal, Mojosari, Kabupaten Mojokerto Terhadap Kuat Tekan Spesi Campuran Semen, Kapur, dan Pasir untuk Pasangan Bata. Jurnal Aplikasi, 12 (2), pp.13-20.

Tucker, M.E. (2003), Sedimentary rock in the field, Third Edition, John Wiley \& Sons Ltd., England, 237 p.

Twenhofel, W.H. (1937), Terminology of the Fine-Grained Mechanical Sediments, National Research Council, Division of Geology and Geography, USA.

Umar, H. (2000), Pengembangan Potensi Bahan Baku Tanah Liat Untuk Industri Gerabah di Kabupaten Takalar Propinsi Sulawesi Selatan, Laporan Penelitian, Lembaga Penelitian Unhas, Makassar. 